OPEN ACCESS

Edited by:

MinJae Lee,

University of Texas Southwestern Medical Center, United States

Reviewed by:

Kuldeep Dhama,

Indian Veterinary Research Institute

(IVRI), India

Bryan Bassig,

National Cancer Institute, National Institutes of Health $(\mathrm{NIH})$,

United States

*Correspondence:

Tigist Gashaw

yekalabel@gmail.com

orcid.org/0000-0002-4419-739X

Specialty section

This article was submitted to

Life-Course Epidemiology and Social

Inequalities in Health,

a section of the journal

Frontiers in Public Health

Received: 13 October 2020

Accepted: 06 April 2021

Published: 05 May 2021

Citation:

Gashaw T, Hagos B and Sisay M

(2021) Expected Impacts of

COVID-19: Considering

Resource-Limited Countries and

Vulnerable Population.

Front. Public Health 9:614789.

doi: 10.3389/fpubh.2021.614789

\section{Expected Impacts of COVID-19: Considering Resource-Limited Countries and Vulnerable Population}

\author{
Tigist Gashaw ${ }^{1 *}$, Bisrat Hagos ${ }^{2}$ and Mekonnen Sisay ${ }^{1}$ \\ ${ }^{1}$ Department of Pharmacology and Toxicology, School of Pharmacy, College of Health and Medical Sciences, Haramaya \\ University, Harar, Ethiopia, ${ }^{2}$ Department of Social Pharmacy, School of Pharmacy, College of Health and Medical Sciences, \\ Haramaya University, Harar, Ethiopia
}

Coronavirus disease in 2019 emerged in Wuhan, Hubei Province, China, in December 2019. After a month, it was declared a global threat to public health. The effects of the pandemic could be socio-economic, undermining the health system and risking livelihoods. Vulnerability to this infection has been associated with underlying comorbidities such as hypertension, diabetes, coronary heart disease, chronic respiratory diseases, cancer, and compromised immune systems. Co-morbidity has been common to the elderly, the disabled, and the homeless. In addition, more severe coronavirus disease outcomes have been reported in older males than females. Nonetheless, multiple variables are related to the concept of cultural gender that should be taken into account as women in more affected sectors are economically disadvantageous and over-represented. Similarly, although children are not the face of this pandemic, calamity has a profound effect on their welfare, especially for those living in poor and inconvenient situations. Moreover, the economic influence could be profound and universal when viewed through a migration lens as it is exacerbating xenophobic and discriminatory treatment. Protection measures to mitigate the outbreak of a pandemic, such as social distancing, may reduce social support for certain categories relied on for their day-to-day activities. The mental health of people would definitely be affected by the additional psychosocial burden of the pandemic, particularly in vulnerable groups. Integrated approaches are therefore mandatory to assist these groups and contain the pandemic.

Keywords: coronavirus, pandemic, impact, comorbidity, vulnerable

\section{INTRODUCTION}

Coronavirus disease in 2019 emerged in Wuhan, Hubei Province, China, in December 2019. After 1 month, as it became highly infectious and spread rapidly to most countries, the World Health Organization (WHO) declared it a global public health threat $(1,2)$. Looking at the case burden, the United States of America is on the frontline, and African countries have a lower rate of accounting (3). However, researchers warned that cases could go undetected in countries with weaker healthcare systems, such as some in Southeast Asia and Africa, which could be quickly stunned by the local epidemic (4). Although it is difficult to predict precisely the consequences of the COVID-19 pandemic, some of the predisposing factors may be elucidated on the basis 
of the experiences of previous pandemics and the already COVID-19-related crises that have been magnified from time to time, mostly in poor countries. Hence, this perspective aims to elucidate the expected impact of COVID-19 in the context of resource-limited countries and vulnerable populations.

\section{IMPACTS OF COVID-19}

\section{Socioeconomic}

Concerns arose about some countries with a modest risk of developing the virus, but whose delicate health systems, economic position, or unstable political situation are increasing vulnerability to the impact of the COVID-19 pandemic, such as Nigeria, Ethiopia, Sudan, Angola, Tanzania, Ghana and Kenya (4). The impact on food security could be rapid and catastrophic, especially for people living in food crises. Potential impacts on food security are mainly linked to movement restrictions, as more than $75 \%$ of them rely on rural farming as a means of support. This may lead to migration and displacement in the search for assistance (5). In addition, the lockdown prevents 300 million school children in Africa from accessing school meals on which their nutrition depends. The situation is even more distressing in East Africa, where coronavirus is hindering efforts to combat one of the largest locust swarms in recent times (6).

The household was also considered a key context in the analysis of the transmission of COVID-19. The mediocre number of families with a resident of more than 65 years of age was significantly higher in low-income countries compared to middle-and high-income countries, increasing the possibility of spread in general and among vulnerable age groups in particular (7).

The threat from COVID-19 has already changed to a drop in the economic and labor market (8). It was suggested that a one percent decline in global economic growth would be interpreted as more than 22 million people prone to poverty (9). Considering Africa as an example, the high dependence of the continent's foreign-referred economies predicts a negative spin-off and is estimated at a 1.5-point average decline in economic growth in 2020. Moreover, the continent is lagging in the transformation of locally available raw materials to respond to the potential high demand for goods and amenities on the internal and global markets (10). In relation, street vending (street food sales and wet market engagement) is an important source of income for many poorer segments of society in urban areas in developing countries. Most people join this business sector to be self-reliant, to support their families, and to lack of opportunities to engage in the formal sector $(11,12)$. Approaches to mitigate the effects of virus-like movement restrictions or physical distances may therefore challenge the livelihoods of these individuals, resulting in food insecurity and malnutrition $(5,13)$.

Another negative impact expected from the COVID-19 pandemic could be explained by the social and political instability associated with the suspension of elections, which could trigger many political actors from opposing parity with the ruling government, generating multidimensional tensions (14). As a result, these effects further fuel societal difficulties in accessing survival requirements and lead to reduced integrity (15-17).

\section{Health System}

The crisis of COVID-19 is spreading to already existing poor health systems and the fragile economy of resource-limited countries (18). Lower ratios of hospital beds, intensive care units, and health professionals to their population, as well as dependence on imported medicinal and pharmaceutical products, could be identified as a problem $(19,20)$. The practice in different nations has highlighted the deep stress that a COVID19 epidemic poses on countrywide health systems, particularly in increasing the need for intensive care facilities everywhere (21). This has a potential impact on resource-scarce areas where the availability and quality of these resources are significantly trivial $(22,23)$. Besides, though there was a prediction of a lower incidence of severe COVID-19 outcome in lower-income countries due to the younger average age, it was likely to be offset by an absence of a sufficient health care system $(7,24)$. Besides, many of them are behind the ability of tests to randomly detect cases that fit their population size.

\section{Vulnerable Population}

\section{Older People With Underlying Co-morbidities}

The crises brought by the COVID-19 pandemic can have an unequal impact on certain sections of the population (25). Various studies are trying to advance the basic determinants of the severity of the infection of COVID-19. Primary factors include age, with the incidence of underlying co-morbidities such as hypertension, diabetes, coronary heart disease, chronic respiratory diseases, cancer, and compromised immune systems commonly used to exacerbate symptoms (26-29). Besides, the deleterious emotional impact of the outbreak may interfere with the clinical outcomes of patients with chronic conditions such as cardiovascular disease and mental illness, whose progress and management are related to anxiety and stress (30). Infection control measures, in particular movement restrictions, will also result in a significant decrease in physical activity and an increase in unhealthful lifestyles, worsening of clinical symptoms of most chronic conditions (31). Up-scaling strategies to ensure adherence to drugs must be another area of concern. Patients who remain in follow-up care are more likely to follow their treatment and experience improved health outcomes $(32,33)$ than those who are not (34) which will likely happen during the COVID-19 pandemic. It is also evident that if the burden of the pandemic is escalating, it will be challenging to treat these patients as lessons from the Ebola pandemic showed a decline in primary medical consultations in more than half of cases (35).

Thus, in order to maximize adherence to drugs, healthcare providers can disseminate health education and drug information to patients by implementing new practices via phone calls, SMS text messaging, and social media platforms. For those who cannot access these technologies, carrier services could be organized for household distributions of essential medicines and prescription refills by strict implementation of all anti-COVID-19 safety protocols (36). In addition, enhancing the role of community pharmacists in managing chronic conditions and maintaining drug adherence during this pandemic is a critical area in alleviating the burden on already stressed health systems (37). Thus, focusing on the virus is justified, a balanced 
approach to avoiding unnecessary morbidity and mortality is imperative (38). Integrated strategies from local health units, community organizations, and healthcare systems are needed to support and contain these vulnerable groups in the event of a pandemic $(33,39-41)$.

\section{Women \\ Biological Implications of Female Sex on COVID-19 Pathogenesis}

Various studies provide evidence that suggests the severity and clinical outcome of COVID-19 infection are more lethal in infected males than females, although sex-disaggregated data in several European countries $(42,43)$ and China (44-46) showed similar prevalence among infected males.

Medical assumptions have been made that the biological effect of the female sex is protective against COVID-19 pathogenesis.

In females, estrogen is responsible for increasing the expression and activity of endothelial nitric oxide synthase (eNOS) and nitric oxide (NO) in the systemic vasculature of females (47). Physiological NO signaling is the main determinant of endothelial function and vascular health. It is the main regulator of the vascular smooth muscle and has anti-inflammatory, antioxidant, and anti-thrombotic activity as well as the defense of the vascular system against vasoactive contractors such as angiotensin II (48). Females are therefore naturally at a lower risk of cardiovascular disease and persistent endothelial dysfunction, which is a major factor in increasing susceptibility to severe acute coronavirus 2 (SARS-CoV-2) infection due to increased levels of angiotensin-converting enzyme 2 (ACE2) (SARS-Cov-2 receptor) exposure to vascular and cardiac pericytes $(49,50)$.

Also, females are identified to produce more innate and adaptive immune responses than males, which may help to clear the virus more quickly (51). The number and activity of innate immune cells, including monocytes, macrophages, dendritic cells, and inflammatory immune responses, are increased in females compared to males (52). And the adaptive immune responses also reveal higher humoral and cell-mediated immune responses to antigenic stimulation, vaccination, and infection than do males (51). Besides, females' immunoglobulin (53) along with antibody responses is steadily superior (54).

\section{Sociocultural Attributes of Gender on COVID-19 and Vice Versa}

Gender is defined as the social and cultural norms, roles, attributes, and behaviors that a society considers appropriate for men and women or boys and girls (55-57). Data indicate an association between comorbidities and severity of COVID$19(58,59)$. Women are generally at a lower risk of developing morbidity than men (60), except for older age groups. Gender differences in risk behaviors have been reported to play a pivotal role in determining the death rate of non-communicable diseases (61). Persistently higher smoking and risky drinking behaviors are associated with men than women worldwide, leading to the development of comorbidities. Moreover, delayed health-seeking behavior and lower rates of hand-washing patterns have been reflected in men and these are also imperative measures in the era of COVID-19 (42).

However, a number of factors are related to gender definition and should be analyzed before a conclusion is made. Regardless of one's socio-economic class, there are systematic gender differences in material well-being, although the degree of inequality varies across countries and over time. As a result, most societies have gender disparities, with males generally holding higher positions in social, economic, and political hierarchies (62). Gender disparity is not merely perpetuated by unequal access to and ownership of material resources. Gender roles and expectations preserve gender identities and restrict the actions of women and men in ways that contribute to discrimination $(63,64)$.

In developing countries, where poverty and social norms create even worse unequal treatment for girls and women, the consequences are likely to be even more serious. Women are prevented from entering the formal sector by cultural traditions, religious seclusion, and illiteracy, as well as a greater devotion to family obligations $(65,66)$. The part of any economy that is neither taxed nor controlled by any kind of government is known as the informal economy (informal sector or gray economy) (67) which offers vital economic opportunities for the vulnerable like women who make up the majority of the informal sector $(68,69)$. Home-based workers (homemade) and street vendors are two major occupations in this sector (70). However, the majority of employees in the gray economy, lack stable jobs, benefits, welfare, or representation $(65,71,72)$.

Moreover, women are highly engaged in the more affected areas of the COVID-19 pandemic (e.g., nurses, janitors) and account for a large proportion of careers (73). Mostly, they do not have access to social protection and are forced to accept an imbalanced burden in the care economy due to the closure of schools or care systems $(74,75)$. Most of them will therefore be engaged in informal sectors predisposed to increased risks of gender-based violence. Due to traditional influences in developing countries, women may not be in a position to make decisions that hinder the ability to obtain information on outbreaks and the availability of services such as sexual and reproductive health services, including family planning (76) resulting in increased unplanned pregnancy.

The burden of the pandemic on women's health is not only limited to reproductive health but also their emotional attachment and concern for their family well-being, along with a decline in social interaction that could lead to mental health complications (77-80).

The influence of gender variables on disease manifestations and outcomes should therefore be thoroughly assessed in every local context, and the impact of these variables should be incorporated into policies and actions that may be implemented at different levels. These measures particularly benefit underprivileged populations and resource-poor communities like us, where women are particularly vulnerable.

\section{Pregnancy}

Based on available information, the risk of COVID-19 during pregnancy seems to have the same as adults and non-pregnant. 
However, caution must be taken as this group of people has a history of higher risk of severe illness when infected with viral respiratory infections, such as influenza. The changes brought by pregnancy may exacerbate the risk of these infections. It is therefore advisable to take maximum care of this special category to protect themselves from illness whenever possible $(28,81)$. A further area of concern will be the protection measures for the pandemic, such as social distancing, which may have a bad attribute in isolation and reduced social support, which may lead to mental distress, involving the COVID-19 related policy guidelines, which should categorically include maternal mental health and well-being as a priority area $(77,82,83)$.

\section{Children}

Children are generally at less risk of more serious diseases and complications compared to adults. However, indirect effects raise questions about their welfare, especially in the poorest countries, and vulnerable situations (84). Rising malnutrition is expected after school closure across the majority of countries where school meals have been a reliable source of daily nutrition $(85,86)$. Increased vulnerability is responsible for external and internal displacement, arrest, and conditions of conflict. A rise in mortality rates associated with decreases in maternal and child health care coverage has also been estimated (87).

In addition, a greater psychological issue may be enforced by movement limitations compared to the physical sufferings caused by the virus. Static and recurrent lifestyle styles are likely to disrupt the behaviors of adolescents, potentially stimulating suffering, intolerance, monotony, agitation, and multi-neuropsychiatric indications. They are also predisposed to domestic violence, abuse, and uncontrolled virtual content (88).

It is expected that policymakers will respond by extending social security programs to cover the most vulnerable children by prioritizing child-centered services to alleviate the effects on this particular population. Besides, it is important to provide meaningful support to parents and caregivers on how to interact with children, address mental health concerns, and build tools to support learning.

\section{Homeless Population}

Living without a home is a major predisposing factor for an unhealthy lifestyle (89). Homeless people often have many complex health issues (the co-existence of physical, mental, and addiction problems) and face several barriers to accessing health care as well as public health information $(90,91)$. In the current COVID-19 pandemic, due to their weakened immune systems, inadequate nutrition and hygiene, and long-term residence in overcrowded shelters, they are at higher risk of contracting infectious diseases and mortality rates with a limited percentage of identification and care (92) implicating that they are a highly vulnerable community $(93,94)$. Moreover, being without a permanent residence address makes it difficult to track and inhibit the spread and treat those in need $(92,95)$. This could lead to less inclusion of the community in search of knowledge during pandemics and thus overlooked by the subsequent policies (96) missing the fact that the safety of these individuals is an important component of handling the broader disaster of public health.

\section{Informal and Migrant Workers}

The disastrous impact on the economy brought by COVID19 could be stretched, intense, and worldwide when observed from migrants' prospects. All measures related to movement restrictions resulted in global economic actions to close to cessation $(97,98)$ fueling the already exiting unemployment and underemployment in young's and informal workers as witnessed during the global financial crisis (99). Migrant workers incline to be susceptible to the loss of jobs and earnings in an economic calamity in their host country higher than inborn employees (100). Numerous migrants have been stuck owing to the postponement of transference and lockdown in labor camps increasing the risk of infection among them (75). However, host countries have permitted visa extensions and momentary amnesty, as well as delayed migrants' spontaneous departure (97). In 2020, remittance flows to developing countries are expected to decline in 2019 by about 20 percent. This may be due to worsening famine and reducing the access of families to vital health services since it is a source of economic sustenance $(101,102)$. The results of the studies also showed a positive significant correlation between per capita gross national income and net migration and the occurrence of total cases of COVID-19 and new cases regularly (103). In evaluating the total and new cases of COVID, the scale of net migration proved to be a possible factor and a positive factor. Xenophobic and racist treatment of migrants may also be aggravated by crises (104).

These activities call for greater vigilance and action by administrators to resolve the problems of migrants by including them in health care, social initiatives, and shielding them from discrimination. Studies also show that the pandemic affects mental health, with extreme symptoms of depression and anxiety in migrant workers $(98,105)$. Therefore, mental health is a critical aspect that needs to be addressed by generating awareness and psychological support.

\section{People Living With Disability}

In terms of greater health needs, individuals living with disabilities (PLWD), including physical, emotional, intellectual, or sensory disabilities, are excluded from accessing health care, resulting in poorer outcomes and disparities (76). To aggravate these discriminations, COVID-19 intimidates primarily in resources restricted to countries where $80 \%$ of PLWD reside and with insufficient capacity to respond to COVID-19 (106, 107). Many of these categories of people are challenged by existing chronic conditions-such as heart disease, diabetes, and obesity-that predispose them to developing and distressing COVID-19 difficulties (108, 109). Studies point out that although some optimistic action has been taken, the needs of people with disabilities have not been fully addressed. Many nations' response to COVID-19 included disability-comprehensive recommendations, but without ensuring implementation (110). So, readiness and response preparation must be inclusive and easy to get to PLWD in tackling key barriers (111). It is also important to disaggregate information related to disability groups during the pandemic for both those who have beaten COVID-19 and those 
who have surrendered to the disease. This will leave lessons and experience in the development and implementation of fitting interventions for imminent public health crises in these vulnerable populations (112).

\section{INTEGRATED STRATEGIC APPROACHES AGAINST THE COVID-19 PANDEMIC AND LESSON LEARNED IN COMBATING THE CRISES MIRRORING WAYS TO SAFEGUARD THE FUTURE}

\section{Mitigation Strategies}

There is a serious need to discover alternative public health prevention methods to control the spread in the absence of treatment for the COVID-19 virus. By realizing that there is no one-size-fits-all solution to managing the outbreak, all countries should increase their level of preparedness and response to various public health scenarios, since each country has its specific contextual strengths and flaws to account for the impact (113). A cohesive strategy against the COVID-19 epidemic was struggling to be developed by many countries with poorer health systems, including lockdown, physical distance interventions, wearing a facemask, and successful case finding (testing and isolation, contact tracing, and quarantine) (114).

Using the modeling approach, limited resource settings were studied to be best served by a combination of early and aggressive case findings and ongoing physical distancing (which alone might prevent the pandemic from $60-95 \%$, if timely and effectively implemented) measures to control the epidemic. But a lockdown may be helpful until combination interventions can be put in place as it is unlikely to reduce annual mortality or healthcare demand (115). It was also concluded that most countries benefited from early intervention (114) along with community involvement, such as active involvement of religious institutions and mobilizing young people to increase public awareness and community-level case detection through the health extension program (116). Moreover, the role of social media has been significant in promoting public health responses to both preparedness and outbreak control by teaming up with the government to deliver clear, simple, and consistent messages (117).

\section{Capacities of Laboratory Facilities Should Be Enhanced}

Despite the rapid increase in the number of COVID-19 cases reported globally, limited molecular laboratory capacity is evident in resource-constraint settings for case diagnosis and overall disease management. As the Ethiopian Public Health Institute (EPHI) shared the experience of the rapid establishment of one of its COVID-19 research laboratories from locally available resources, the optimal use of existing resources and the repurposing of other sources for human medical treatment could be considered as a preferable approach to the management of restricted facilities $(118,119)$.

\section{Healthcare Systems Values That Need to Be Maximized}

Health is a prerequisite for living a "good life." to achieve other goals that people want to pursue in life. The universal healthcare system should therefore seek to provide the population with a comprehensive concept of health, including the participation of patients in the delivery of care, the best possible use of available resources, the equitable distribution of resources across all patient groups, and the contribution of healthcare to social participation and connectivity (120). In addition, as a strategic objective, the health system should value dynamic leadership driven by transparency and enhancement of value (121). These principles of the health care system will result in a predictive, personalized, preventive, participatory, and psychocognitive medicine (122) that is essential in the Pandemic Control Intervention of COVID-19.

\section{Attentions of Internationally Funding Organizations}

The goals of the Global Humanitarian Response Plan are to maximize coherence and provide an efficient and effective humanitarian response that, through active community participation, will be incorporated into all of the nations' current intervention response plans. The guiding principle for these humanitarian activities is a people-centered approach and inclusiveness, especially for the most vulnerable, stigmatized, hard-to-reach, displaced and mobile populations marginalized in national plans. Also, a tailored response will be given to the needs of different age groups (children, the elderly) as well as to gender equality, in particular, to address the unique needs of women and girls, the risks and roles of providing care, increased exposure to movement-restricted gender-based violence and a large number of female frontline health workers in this pandemic response $(119,123-125)$.

\section{Vaccine Policy}

Implementing national-level vaccination programs involves long-term investment, which can be a significant financial burden, particularly in resource-limited settings (126). Reports revealed that, before the start of marketing, high-income countries had made deals to buy COVID-19 vaccines but left the rest of the world with unclear access. The uncertainty of global access to COVID-19 vaccines is due not only to ongoing clinical trials but also to the inability of governments and vaccine manufacturers to be more transparent and accountable for these arrangements, from equal pricing to fair allocation (127). This will also present threats of corruption that could jeopardize critical public health objectives. These concerns include the provision of counterfeit and substandard vaccines, theft, nepotism, racism, and corrupt procurement processes. Responsible authorities are indeed required to act to prevent corruption in the production, allocation, and distribution of vaccines in the supply chain (128-130).

In order to help solve some of the related problems, SAGE (The Strategic Advisory Group of Experts on Immunization) proposes a prioritization roadmap for COVID-19 vaccines 
that considers priority groups for vaccine versions based on epidemiological settings, vaccine supply scenarios, and the context of the overall public health strategy for each epidemiological setting (131-133). The WHO has also established the principle that vaccines for COVID-19 must be a global public good. The key objective of COVID-19 vaccines is to contribute significantly to the equitable protection and promotion of human well-being, based on reciprocity and legitimacy for all people around the world, at the global and national level $(130,133,134)$. Besides, focus should be put on older adults, pregnant and lactating mothers in clarifying gender-based biological disparities in the efforts of vaccine production clinical trials to ensure safety and efficacy $(135,136)$.

Currently, three vaccines are authorized and recommended to prevent COVID-19: Pfizer-BioNTech, Moderna, and Janssen. As of February 2021, large-scale (Phase 3) clinical trials are in progress or being planned for two COVID-19 vaccines in the United States: AstraZeneca COVID-19 vaccine and Novavax COVID-19 vaccine. Forecasting vaccine and logistics needs, evaluating available storage space, defining surge capacity, developing a delivery plan, reinforcing supply and stock management, implementing a vaccine traceability system, and planning for vaccine protection and concerned workers are among the main approaches proposed for vaccine deployment. Furthermore, many low- and middleincome countries will face many challenges when it comes to COVID-19 vaccines with an ultracold chain (UCC) $\left(-60^{\circ} \mathrm{C}\right.$ to $-90^{\circ} \mathrm{C}$ degrees $\left.{ }^{\circ} \mathrm{C}\right)$ profile, including a lack of current UCC equipment in health/immunization systems, including phase change material (PCM) and facilities to manufacture dry ice; high investment costs due to the timelimited existence of the need for UCC capability-many countries will aim to move to vaccines that can be stored at $+2^{\circ} \mathrm{C}$ to $+8^{\circ} \mathrm{C}$; and difficult handling and distribution requirements, especially where UCC products have limited shelf lives (e.g., 7 days) when stored at +2 to +8 degrees Celsius. As a result, countries in need of UCC can consider feasible options such as utilizing existing internal and/or external resources (137-142).

\section{Lesson Learned in Combating the Pandemic, Outlook, and Preparedness to Safeguard the Future}

To plan for potential outbreaks, countries should draw on lessons from COVID-19. This pandemic has restated the prominence of the saying "prevention is better than cure" and has trained mankind mentally to fight and battle this pandemic. It also revealed weak points about how we're thinking about health and preparing for the disease. It has also created an ability to enhance our services and health care systems and learn how to be better positioned for the next emergency (116). On the other hand, by taking advantage of the opportunity provided by the current pandemic, different settings have benefited from the establishment of an additional standard molecular laboratory, trained staff as well as the attribution of human and material resources that could last beyond the COVID-19 era (118).

A further limitation noted in the health sector was the lack of a harmonized approach to data governance and global standards for terminology and sharing of health data. It must be improved so that it can provide usable and accessible national and global data for surveillance and emergency response without neglecting confidentiality (143).

The fundamental link between human factors, development, and technology was also exposed to the pandemic of COVID19. Healthcare programs are structured to ensure health security and progress in the health sector, but they are too often under-funded, under-employed, stressed, and placed at the bottom of the political agenda. In addition to stemming this outbreak, efforts should therefore be made to develop comprehensive measures to prevent future outbreaks (116) by maintaining biosecurity, through the One Health Approach (to achieve the best health outcomes for humans, animals, and the environment) and by providing information on recent developments (144). Ultimately, the magnitude of the crisis will be determined by our mutual ability to recognize and respond to these interdependencies through integrated strategies to control COVID-19, including vaccination, molecular and serological diagnosis, hygiene and $\mathrm{WaSH}$ (water, sanitation, and hygiene) interventions, and low-cost therapeutics (145152). These aspirations should be at the heart of the health inclinations of the global community in the post-COVID-19 era (153). Besides, psychosocial risk mitigation should be a key focus, and policymakers can give priority to working on a simple yet cost-effective organizational exercise to enhance disaster coping mechanisms $(149,150)$.

Further research focusing on the screening, identification, isolation, and characterization of coronavirus $(\mathrm{CoV})$ in wildlife species, particularly in bats, should be continued through both in vitro and in vivo methods, as emerging patterns suggest future outbreaks of $\mathrm{CoV}$ due to climate change and ecological conditions that may be associated with human-animal contact (154-156). Moreover, post-marketing surveillance should be considered for the tracking and evaluation of approved vaccines.

\section{CONCLUSION}

The impacts of COVID-19 have been revealed multidimensionality including socioeconomic, weakening the health system, and increasing the vulnerability of some segment of the population. Developing appropriate strategic measures, keeping and upscaling food security interventions, and protecting the livings of the most vulnerable people such as those with underlying co-morbidities, children, homeless, women, pregnant, migrants, and people with disabilities need to be top priority. Supporting cities and local managements in their actions to mitigate the calamity by sharing and increasing involvement is also central. Methods to evaluate the effectiveness of current health interventions combined with a high level of testing proportional to countries population size 
should also be accentuated. Moreover, the interrelationship between characteristics of high-risk populations for impact of COVID-19 and health outcomes and prompt consideration of these variables in both research, clinical practice, and vaccine development should be acknowledged. Moreover, COVID-19 vaccines must be a global public good that is aimed to contribute significantly to the equitable protection and promotion of human well-being at the global and national level based on reciprocity and legitimacy. When the crisis ends, countries should draw lessons from COVID-19 to prepare for future outbreaks.

\section{REFERENCES}

1. Zhu R-f, Gao R-l, Robert S-H, Gao J-p, Yang S-g, Zhu C. Systematic review of the registered clinical trials of Coronavirus Disease 2019 (COVID-19). medRxiv. (2020) 18:274. doi: 10.1101/2020.03.01.20029611

2. Luo H, Tang Q-l, Shang Y-x, Liang S-b, Yang M, Robinson N, et al. Can Chinese medicine be used for prevention of corona virus disease 2019 (COVID-19)? A review of historical classics, research evidence and current prevention programs. Chin J Integr Med. (2020) 26:24350. doi: 10.1007/s11655-020-3192-6

3. Worldometers. COVID-19 Coronavirus Pandemic. Genève: WHO (2020).

4. Mallapaty S. Scientists Fear Coronavirus Spread in Vulnerable Nations. London: Nature Publishing Group (2020).

5. Ranscombe P. Rural areas at risk during COVID-19 pandemic. Lancet Infect Dis. (2020) 20:545. doi: 10.1016/S1473-3099(20)30301-7

6. Zurayk R. Pandemic and food security. J Agric Food Syst Commun Dev. (2020) 9:1-5. doi: 10.5304/jafscd.2020.093.014

7. Walker P, Whittaker C, Watson O. The Global Impact of COVID-19 and Strategies for Mitigation and Suppression: WHO Collaborating Centre for Infectious Disease Modelling. London: MRC Centre for Global Infectious Disease Analysis, Abdul Latif Jameel Institute for Disease and Emergency Analytics, Imperial College London (2020). Available online at: https://www. imperial.ac.uk $>$ report-12-global-impact-c

8. McKibbin W, Fernando R. 3 The Economic Impact of COVID-19. In: Economics in the Time of COVID-19. London: CEPR Press Centre for Economic Policy Research (2020). p. 45. Available online at: www.cepr.org

9. Lucas B. Impacts of Covid-19 on Inclusive Economic Growth in Middle-income Countries. K4D Helpdesk Report 811. Brighton: Institute of Development Studies (2020).

10. Union A. Impact of the Coronavirus Covid-19 on the African Economy. Adis Abeba: African Union (2020).

11. Jonga W. Street vending at megenagna (Ethiopia): challenges and prospects. Rev Manage Innov Creat. (2012) 5:50-69. Available online at: http://search. ebscohost.com

12. Wodaje B, Zenebe K, Terefe Y, Northcut TB. Assessment of challenges and prospects of women petty traders: a survey study in Harar, Jigjiga, and Dire Dawa, Ethiopia. Soc Dev Issues. (2019) 41:41-56. Available online at: https:// www.researchgate.net/publication/337831151

13. Galanakis CM. The food systems in the era of the Coronavirus (COVID-19) pandemic crisis. Foods. (2020) 9:523. doi: 10.3390/foods 9040523

14. Chukwueloke E, Oghuvbu EA. The corona-virus pandemic and its impacts on human security in West Africa. Acta Univ Danubius Relationes Int. (2020) 13:36-46. Available online at: https://dj.univ-danubius.ro/index.php/ AUDRI/article/view/329

15. Renzaho A. The need for the right socio-economic and cultural fit in the COVID-19 response in Sub-Saharan Africa: examining demographic, economic political, health, and socio-cultural differentials in COVID19 morbidity and mortality. Int J Environ Res Public Health. (2020) 17:3445. doi: 10.3390/ijerph17103445

16. Megersa K. COVID-19 in Eastern Africa: Impact Analysis on Conflict and Security. K4D Helpdesk Report 847. Brighton: Institute of Development

\section{DATA AVAILABILITY STATEMENT}

The original contributions generated for this study are included in the article/supplementary material, further inquiries can be directed to the corresponding author/s.

\section{AUTHOR CONTRIBUTIONS}

TG drafted the document and prepared the final version for publication. All authors had substantial contributions to the document, read and approved the final version of the manuscript.

Studies (2020). Available online at: https://opendocs.ids.ac.uk/opendocs/ handle/20.500.12413/15549

17. Kassa MD, Grace JM. Race against death or starvation? COVID19 and its impact on African populations. Public Health Rev. (2020) 41:30. doi: 10.1186/s40985-020-00139-0

18. Debela BK. The COVID-19 Pandemic and the Ethiopian Public Administration: Responses and Challenges. Addis Ababa: Leuven University Press (2020).

19. Kitenge SY. Globalization and the COVID-19 Pandemic: How is Africa's Economy Impacted? New York, NY: United Nations Africa Renewal (2020).

20. Phua J, Faruq MO, Kulkarni AP, Redjeki IS, Detleuxay K, Mendsaikhan N, et al. Critical care bed capacity in Asian countries and regions. Crit Care Med. (2020) 48:654-62. doi: 10.1097/CCM.0000000000004222

21. Remuzzi A, Remuzzi G. COVID-19 and Italy: what next? Lancet. (2020) 395:1225-8. doi: 10.1016/S0140-6736(20)30627-9

22. Shammi M, Bodrud-Doza M, Towfiqul Islam ARM, Rahman MM. COVID-19 pandemic, socioeconomic crisis and human stress in resource-limited settings: a case from Bangladesh. Heliyon. (2020) 6:e04063. doi: 10.1016/j.heliyon.2020.e04063

23. Ginsburg AS, Van Cleve WC, Thompson MI, English M. Oxygen and pulse oximetry in childhood pneumonia: a survey of healthcare providers in resource-limited settings. J Trop Pediatr. (2012) 58:38993. doi: $10.1093 /$ tropej/fmr103

24. Sehoole TJ. COVID-19: Pandemic burden in Sub-Saharan Africa and the right to health - The need for advocacy in the face of growing privatisation. Afr J Prim Health Care Fam Med. (2020) 12:2476. doi: 10.4102/phcfm.v12i1.2476

25. Benjamin GC. Ensuring health equity during the COVID-19 pandemic: the role of public health infrastructure. Rev Panam Salud Publica. (2020) 44:e70. doi: 10.26633/RPSP.2020.70

26. Anand V, Thangavelu S, Fathah Z, Ravindran P, Sanjeev A, Babu S, et al. COVID-19 and the world with co-morbidities of heart disease, hypertension and diabetes. J Pure Appl Microbiol. (2020) 14:162338. doi: 10.22207/JPAM.14.3.01

27. Dhama K, Patel SK, Kumar R, Rana J, Yatoo MI, Kumar A, et al. Geriatric population during COVID-19 pandemic: problems, considerations, exigencies and beyond Head Title: Geriatrics during COVID-19 pandemic. Front Public Health. (2020) 8:562. doi: 10.3389/fpubh.2020.574198

28. Dashraath P, Jeslyn WJL, Karen LMX, Min LL, Sarah L, Biswas A, et al. Coronavirus disease 2019 (COVID-19) pandemic and pregnancy. Am J Obstet Gynecol. (2020) 222:521-31. doi: 10.1016/j.ajog.2020.03.021

29. Hall V, Thomsen RW, Henriksen O, Lohse N. Diabetes in Sub Saharan Africa 1999-2011: epidemiology and public health implications. a systematic review. BMC Public Health. (2011) 11:564. doi: 10.1186/1471-2458-11-564

30. Mariotti A. The effects of chronic stress on health: new insights into the molecular mechanisms of brain-body communication. Future Sci OA. (2015) 1:FSO23. doi: 10.4155/fso.15.21

31. Palmer K, Monaco A, Kivipelto M, Onder G, Maggi S, Michel J-P, et al. The potential long-term impact of the COVID-19 outbreak on patients with noncommunicable diseases in Europe: consequences for healthy ageing. Aging Clin Exp Res. (2020) 32:1189-94. doi: 10.1007/s40520-020-01601-4 
32. Pinto RM, Park S. COVID-19 pandemic disrupts HIV continuum of care and prevention: implications for research and practice concerning communitybased organizations and frontline providers. AIDS Behav. (2020) 24:24869. doi: 10.1007/s10461-020-02893-3

33. Ridgway JP, Schmitt J, Friedman E, Taylor M, Devlin S, McNulty M, et al. HIV care continuum and COVID-19 outcomes among people living with HIV during the COVID-19 pandemic, Chicago, IL. AIDS Behav. (2020) 24:2770-2. doi: 10.1007/s10461-020-02905-2

34. Gelaw BK, Mohammed A, Tegegne GT, Defersha AD, Fromsa M, Tadesse E, et al. Nonadherence and contributing factors among ambulatory patients with antidiabetic medications in adama referral hospital. J Diabetes Res. (2014) 2014:617041. doi: 10.1155/2014/617041

35. Lone SA, Ahmad A. COVID-19 pandemic - an African perspective. Emerg Microb Infect. (2020) 9:1300-8. doi: 10.1080/22221751.2020.1775132

36. Chersich MF, Gray G, Fairlie L, Eichbaum Q, Mayhew S, Allwood B, et al. COVID-19 in Africa: care and protection for frontline healthcare workers. Global Health. (2020) 16:46. doi: 10.1186/s12992-020-00574-3

37. Kretchy IA, Asiedu-Danso M, Kretchy J-P. Medication management and adherence during the COVID-19 pandemic: perspectives and experiences from LMICs. Res Soc Adm Pharm. (2021) 17:2023-6. doi: 10.1016/j.sapharm.2020.04.007

38. Shigute Z, Mebratie AD, Alemu G, Bedi AS. COVID-19 and balance in access to health care in Ethiopia. Clin Epidemiol Global Health. (2020) 9:1. doi: 10.1016/j.cegh.2020.05.013

39. Mobula LM, Heller DJ, Commodore-Mensah Y, Walker Harris V, Cooper LA. Protecting the vulnerable during COVID-19: Treating and preventing chronic disease disparities. Gates Open Res. (2020) 4:125. doi: 10.12688/gatesopenres.13181.1

40. Jiang $H$, Zhou $Y$, Tang W. Maintaining HIV care during the COVID-19 pandemic. Lancet HIV. (2020) 7:e3089. doi: 10.1016/S2352-3018(20)30105-3

41. Singh AK, Misra A. Impact of COVID-19 and comorbidities on health and economics: focus on developing countries and India. Diabetes Metab Syndr. (2020) 14:1625-30. doi: 10.1016/j.dsx.2020.08.032

42. Gebhard C, Regitz-Zagrosek V, Neuhauser HK, Morgan R, Klein SL. Impact of sex and gender on COVID-19 outcomes in Europe. Biol Sex Differ. (2020) 11:29. doi: 10.1186/s13293-020-00304-9

43. Dangis A, De Brucker N, Heremans A, Gillis M, Frans J, Demeyere A, et al. Impact of gender on extent of lung injury in COVID-19. Clini Radiol. (2020) 75:554-6. doi: 10.1016/j.crad.2020.04.005

44. Guan W-j, Ni Z-y, Hu Y, Liang W-h, Ou C-q, He J-x, et al. Clinical characteristics of coronavirus disease 2019 in China. N Engl J Med. (2020) 382:1708-20. doi: 10.1056/NEJMoa2002032

45. Zhao S, Cao P, Chong M, Gao D, Lou Y, Ran J, et al. The time-varying serial interval of the coronavirus disease (COVID-19) and its gender-specific difference: a data-driven analysis using public surveillance data in Hong Kong and Shenzhen, China from January 10 to February 15, 2020. Infect Control Hosp Epidemiol. (2020) 10:1-8. doi: 10.1017/ice.2020.64

46. Mo P, Xing Y, Xiao Y, Deng L, Zhao Q, Wang H, et al. Clinical characteristics of refractory COVID-19 pneumonia in Wuhan, China. Clin Infect Dis. (2020) ciaa270. doi: 10.1093/cid/ciaa270. [Epub ahead of print].

47. Nevzati E, Shafighi M, Bakhtian KD, Treiber H, Fandino J, Fathi AR. Estrogen induces nitric oxide production via nitric oxide synthase activation in endothelial cells. In: Fandino J, Marbacher S, Fathi A-R, Muroi C, Keller E, editors. Neurovascular Events After Subarachnoid Hemorrhage: Towards Experimental and Clinical Standardisation. Cham: Springer International Publishing (2015). p. 141-5. doi: 10.1007/978-3-319-04981-6_24

48. Ozdemir B, Yazici A. Could the decrease in the endothelial nitric oxide (NO) production and NO bioavailability be the crucial cause of COVID-19 related deaths? Med Hypotheses. (2020) 144:109970. doi: 10.1016/j.mehy.2020.109970

49. Rabelo LA, Todiras M, Nunes-Souza V, Qadri F, Szijártó IA, Gollasch M, et al. Genetic deletion of ACE2 induces vascular dysfunction in C57BL/6 mice: role of nitric oxide imbalance and oxidative stress. PLOS ONE. (2016) 11:e0150255. doi: 10.1371/journal.pone.0150255

50. He L, Mäe MA, Muhl L, Sun Y, Pietilä R, Nahar K, et al. Pericyte-specific vascular expression of SARS-CoV-2 receptor ACE2 - implications for microvascular inflammation and hypercoagulopathy in COVID-19. bioRxiv. (2020). doi: 10.1101/2020.05.11.088500

51. Klein SL. Sex influences immune responses to viruses, and efficacy of prophylaxis and treatments for viral diseases. Bioessays. (2012) 34:10509. doi: 10.1002/bies.201200099

52. Xia H-J, Zhang G-H, Wang R-R, Zheng Y-T. The influence of age and sex on the cell counts of peripheral blood leukocyte subpopulations in Chinese rhesus macaques. Cell Mol Immunol. (2009) 6:433-40. doi: 10.1038/cmi.2009.55

53. Butterworth $M$, McClellan B, Allansmith $M$. Influence of sex in immunoglobulin levels. Nature. (1967) 214:1224-5. doi: 10.1038/2141224a0

54. Cook IF. Sexual dimorphism of humoral immunity with human vaccines. Vaccine. (2008) 26:3551-5. doi: 10.1016/j.vaccine.2008.04.054

55. Valenzuela A. Gender roles and settlement activities among children and their immigrant families. Am Behav Sci. (1999) 42:720-42. doi: 10.1177/0002764299042004009

56. Heise L, Greene ME, Opper N, Stavropoulou M, Harper C, Nascimento M, et al. Gender inequality and restrictive gender norms: framing the challenges to health. Lancet. (2019) 393:2440-54. doi: 10.1016/S0140-6736(19)30652-X

57. Blee KM, Tickamyer AR. Racial differences in men's attitudes about women's gender roles. J Marriage Fam. (1995) 57:21-30. doi: 10.2307/353813

58. Sharma G, Volgman AS, Michos ED. Sex differences in mortality from COVID-19 pandemic: are men vulnerable and women protected? JACC Case Rep. (2020) 2:1407-10. doi: 10.1016/j.jaccas.2020.04.027

59. Hall KS, Samari G, Garbers S, Casey SE, Diallo DD, Orcutt M, et al. Centring sexual and reproductive health and justice in the global COVID-19 response. Lancet. (2020) 395:1175-7. doi: 10.1016/S0140-6736(20)30801-1

60. James SL, Abate D, Abate KH, Abay SM, Abbafati C, Abbasi N, et al. Global, regional, and national incidence, prevalence, and years lived with disability for 354 diseases and injuries for 195 countries and territories, 1990-2017: a systematic analysis for the Global Burden of Disease Study 2017. Lancet. (2018) 392:1789-858. doi: 10.1016/S0140-6736(17)32154-2

61. Cai H. Sex difference and smoking predisposition in patients with COVID19. Lancet Respir Med. (2020) 8:e20. doi: 10.1016/S2213-2600(20)30117-X

62. Cassar A, Katz E. Gender, behavior, and women's economic empowerment. CGD Background Paper. (2016) 1-29. Available online at: https://www. empowerwomen.org/en/resources/documents

63. Kangas A, Haider H, Fraser E. Gender: Topic Guide. Revised edition with E Browne. Birmingham: GSDRC, University of Birmingham, UK (2014).

64. Marcus R, Harper C, Brodbeck S, Page E. Social Norms, Gender Norms and Adolescent Girls: A Brief Guide. London: Overseas Development Institute (2015).

65. Jahiruddin A, Short P, Dressler W, Khan MA. Can microcredit worsen poverty? Cases of exacerbated poverty in Bangladesh. Dev Pract. (2011) 21:1109-21. doi: 10.1080/09614524.2011.607155

66. Harper C, Marcus R. What can a focus on gender norms contribute to girls'empowerment? Adolesc Girls Dev Ctries. (2018) 22. doi: 10.4324/9781315180250-2

67. Alasfour F. Costs of distrust: the virtuous cycle of tax compliance in Jordan. J Bus Ethics. (2019) 155:243-58. doi: 10.1007/s10551-017-3473-y

68. Udoh E. Taxing the informal economy in Nigeria: Issues, challenges and opportunities. Int J Bus Soc Sci. (2015) 6:160-75. Available online at: https:// ijbssnet.com

69. Becchio G. Behavioral economics, gender economics, and feminist economics: friends or foes? J Econ Methodol. (2019) 26:259-71. doi: 10.1080/1350178X.2019.1625218

70. Chen MA. Women and informality: a global picture, the global movement. Sais Rev. (2001) 21:71-82. doi: 10.1353/sais.2001.0007

71. Benería L, Floro MS. Labour market informalization, gender and social protection: reflections on poor urban households in Bolivia and Ecuador. In: Razavi S, Hassim S, editors. Gender and Social Policy in a Global Context: Uncovering the Gendered Structure of 'the Social'. London: Palgrave Macmillan UK (2006). p. 193-216. doi: 10.1057/97802306 25280_9

72. Mackie P, Brown A, Dickenson K, Ahmed E, Ahmed Hassan S, Mohamoud Barawani MA. Informal economies, conflict recovery and absent aid. Environ Urban. (2017) 29:365-82. doi: 10.1177/0956247817719868 
73. Langer A, Meleis A, Knaul FM, Atun R, Aran M, Arreola-Ornelas H, et al. Women and health: the key for sustainable development. Lancet. (2015) 386:1165-210. doi: 10.1016/S0140-6736(15)60497-4

74. Wenham C, Smith J, Morgan R. COVID-19: the gendered impacts of the outbreak. Lancet. (2020) 395:846-8. doi: 10.1016/S0140-6736(20)30526-2

75. Berg J, Furrer M, Harmon E, Rani U, Silberman MS. Digital Labour Platforms and the Future of Work. Towards Decent Work in the Online World Rapport de l'OIT. Genève: International Labour Organization (ILO) (2018).

76. Farrington M, Fal Dutra Santos R. Resources for Community Engagement during Covid-19. Oxfam (2020). Available online at: http://hdl.handle.net/ $10546 / 620977$

77. Gausman J, Langer A. Sex and gender disparities in the COVID-19 pandemic. J Womens Health. (2020) 29:465-6. doi: 10.1089/jwh.2020.8472

78. Alonzi S, La Torre A, Silverstein MW. The psychological impact of preexisting mental and physical health conditions during the COVID-19 pandemic. Psychol Trauma. (2020) 12:S236-8. doi: 10.1037/tra0000840

79. Özdin S, Bayrak Özdin S. Levels and predictors of anxiety, depression and health anxiety during COVID-19 pandemic in Turkish society: the importance of gender. Int J Soc Psychiatry. (2020) 66: 50411. doi: $10.1177 / 0020764020927051$

80. Liu N, Zhang F, Wei C, Jia Y, Shang Z, Sun L, et al. Prevalence and predictors of PTSS during COVID-19 outbreak in China hardest-hit areas: Gender differences matter. Psychiatry Res. (2020) 287:112921. doi: 10.1016/j.psychres.2020.112921

81. Liang H, Acharya G. Novel corona virus disease (COVID-19) in pregnancy: what clinical recommendations to follow? Acta Obstet Gynecol Scand. (2020) 99:439-42. doi: 10.1111/aogs.13836

82. Favre G, Pomar L, Musso D, Baud D. 2019-nCoV epidemic: what about pregnancies? Lancet. (2020) 395:e40. doi: 10.1016/S0140-6736(20)30311-1

83. Shidhaye R, Madhivanan P, Shidhaye P, Krupp K. An integrated approach to improve maternal mental health and well-being during the COVID-19 crisis. Front Psychiatry. (2020) 11:598746. doi: 10.3389/fpsyt.2020.598746

84. Fore HH. A wake-up call: COVID-19 and its impact on children's health and wellbeing. Lancet Global Health. (2020) 8:e861-2. doi: 10.1016/S2214-109X(20)30238-2

85. UNICEF. Policy Brief: the Impact of COVID-19 on Children. New York: United Nations Children's Fund (2020).

86. Headey D, Heidkamp R, Osendarp S, Ruel M, Scott N, Black R, et al. Impacts of COVID-19 on childhood malnutrition and nutrition-related mortality. Lancet. (2020) 396:519-21. doi: 10.1016/S0140-6736(20)31647-0

87. Roberton T, Carter ED, Chou VB, Stegmuller AR, Jackson BD, Tam $\mathrm{Y}$, et al. Early estimates of the indirect effects of the COVID-19 pandemic on maternal and child mortality in low-income and middleincome countries: a modelling study. Lancet Global Health. (2020) 8:e9018. doi: 10.1016/S2214-109X(20)30229-1

88. Ghosh R, Dubey MJ, Chatterjee S, Dubey S. Impact of COVID-19 on children: special focus on psychosocial aspect. Education. (2020) 31:34. doi: 10.23736/S0026-4946.20.05887-9

89. Culhane D, Treglia D, Steif K, Kuhn R, Byrne T. Estimated emergency and observational/quarantine capacity need for the US homeless population related to COVID-19 exposure by county; projected hospitalizations, intensive care units and mortality. UCLA. (2020). Available online at: https:// works.bepress.com/dennis_culhane/237/

90. Kolloju N. Prevalence and Correlates of Substance Use Disorders in Patients With Schizophrenia. Vellore: Christian Medical College (2018).

91. Tsai J, Gelberg L, Rosenheck RA. Changes in physical health after supported housing: results from the collaborative initiative to end chronic homelessness. J Gen Intern Med. (2019) 34:1703-8. doi: 10.1007/s11606-019-05070-y

92. Tsai J, Wilson M. COVID-19: a potential public health problem for homeless populations. Lancet Public Health. (2020) 5:e186-7. doi: 10.1016/S2468-2667(20)30053-0

93. Albon D, Soper M, Haro A. Potential implications of the COVID19 pandemic on the homeless population. Chest. (2020) 158:4778. doi: 10.1016/j.chest.2020.03.057

94. Perri M, Dosani N, Hwang SW. COVID-19 and people experiencing homelessness: challenges and mitigation strategies. CMAJ. (2020) 192:E7169. doi: $10.1503 / \mathrm{cmaj} .200834$
95. Corburn J, Vlahov D, Mberu B, Riley L, Caiaffa WT, Rashid SF, et al. Slum health: arresting COVID-19 and improving wellbeing in urban informal settlements. J Urban Health. (2020) 97:348-57. doi: 10.1007/s11524-020-00438-6

96. Banerjee D, Bhattacharya $\mathrm{P}$. The hidden vulnerability of homelessness in the COVID-19 pandemic: perspectives from India. Int J Soc Psychiatry. (2020) 20764020922890. doi: 10.1177/0020764020922890

97. Ratha DK, De S, KimEJ, Plaza S, Seshan GK, Yameogo ND. COVID-19 Crisis Through a Migration Lens. Washington, DC: World Bank Group; The Global Knowledge Partnership on Migration and Development (KNOMAD) (2020).

98. Kumar K, Mehra A, Sahoo S, Nehra R, Grover S. The psychological impact of COVID-19 pandemic and lockdown on the migrant workers: a cross-sectional survey. Asian J Psychiatr. (2020) 53:102252. doi: 10.1016/j.ajp.2020.102252

99. Lee A, Cho J. The impact of epidemics on labor market: identifying victims of the Middle East Respiratory Syndrome in the Korean labor market. Int J Equity Health. (2016) 15:196. doi: 10.1186/s12939-016-0483-9

100. Borjas GJ, Cassidy H. The adverse effect of the covid-19 labor market shock on immigrant employment. Natl Bur Econ Res. (2020) 08982937. doi: 10.3386/w27243. Available online at: http://www.nber.org/dataappendix/w27243

101. Salik KM. Policy Review Remittances and COVID-19: Is Pakistan Ready for a Likely Decline in Flows?. Islamabad: Government of Pakistan (2020). Available online at: https://covid.gov.pk/

102. Abel G, Gietel-Basten S. International remittance flows and the economic and social consequences of COVID-19. Environ Plan A. (2020) 52:0308518X20931111. doi: 10.1177/0308518X20931111

103. Varkey RS, Joy J, Sarmah G, Panda PK. Socioeconomic determinants of COVID-19 in Asian countries: an empirical analysis. J Public Aff. (2020) e2532. doi: 10.1002/pa.2532. [Epub ahead of print].

104. Guadagno L. Migrants and the COVID-19 pandemic: an initial analysis. Int Organ Migr Migr Res Ser. International Organization for Migration (2020) 60:28. Available online at: https://reliefweb. intŻreportŻworldŻmigrants-and-co

105. Choudhari R. COVID 19 pandemic: Mental health challenges of internal migrant workers of India. Asian J Psychiatry. (2020) 54:102254. doi: 10.1016/j.ajp.2020.102254

106. The L. Prioritising disability in universal health coverage. Lancet. (2019) 394:187. doi: 10.1016/S0140-6736(19)31638-1

107. Shadmi E, Chen Y, Dourado I, Faran-Perach I, Furler J, Hangoma P, et al. Health equity and COVID-19: global perspectives. Int J Equity Health. (2020) 19:104. doi: 10.1186/s12939-020-01218-z

108. Senjam SS. Impact of COVID-19 pandemic on people living with visual disability. Indian $J$ Ophthalmol. (2020) 68:1367. doi: 10.4103/ijo.IJO_1513 20

109. Eskyte I, Lawson A, Orchard M, Andrews E. Out on the streets-crisis, opportunity and disabled people in the era of covid-19: reflections from the UK. Alter. (2020) 14:329-36. doi: 10.1016/j.alter.2020.07.004

110. Sakellariou D, Malfitano APS, Rotarou ES. Disability inclusiveness of government responses to COVID-19 in South America: a framework analysis study. Int J Equity Health. (2020) 19:131. doi: 10.1186/s12939-020-01244-x

111. Armitage R, Nellums LB. The COVID-19 response must be disability inclusive. Lancet Public Health. (2020) 5:e257. doi: 10.1016/S2468-2667(20)30076-1

112. Hassiotis A, Ali A, Courtemanche A, Lunsky Y, McIntyre LL, Napolitamo D, et al. In the time of the pandemic: safeguarding people with developmental disabilities against the impact of coronavirus. J Ment Health Res Intellect Disabil. (2020) 13:63-5. doi: 10.1080/19315864.2020.1756080

113. Group GC-S. Combating the COVID-19 pandemic in a resourceconstrained setting: insights from initial response in India. BMJ Global Health. (2020) 5:e003416. doi: 10.1136/bmjgh-2020-003416

114. Bong C-L, Brasher C, Chikumba E, McDougall R, Mellin-Olsen J, Enright A. The COVID-19 pandemic: effects on low- and middle-income countries. Anesth Analg. (2020) 131:86-92. doi: 10.1213/ANE.00000000000 04846

115. Pandey KR, Subedee A, Khanal B, Koirala B. COVID-19 control strategies and intervention effects in resource limited settings: a modeling study. medRxiv. (2020). doi: 10.1101/2020.04.26.20079673 
116. Getaneh Y, Yizengaw A, Adane S, Zealiyas K, Abate Z, Leulseged $S$, et al. Global lessons and Potential strategies in combating COVID-19 pandemic in Ethiopia: systematic review. medRxiv. (2020). doi: 10.1101/2020.05.23.20111062

117. Hopman J, Allegranzi B, Mehtar S. Managing COVID-19 in Low- and Middle-Income Countries. JAMA. (2020) 323:154950. doi: 10.1001/jama.2020.4169

118. Abera A, Belay H, Zewude A, Gidey B, Nega D, Dufera B, et al. Establishment of COVID-19 testing laboratory in resource-limited settings: challenges and prospects reported from Ethiopia. Global Health Action. (2020) 13:1841963. doi: 10.1080/16549716.2020.18 41963

119. Wallace LJ, Nouvet E, Bortolussi R, Arthur JA, Amporfu E, Arthur E, et al. COVID-19 in sub-Saharan Africa: impacts on vulnerable populations and sustaining home-grown solutions. Can J Public Health. (2020) 111:64953. doi: 10.17269/s41997-020-00399-y

120. Wallang P. Volumising value: value-based healthcare and its coming of age. BJPsych Adv. (2020) 26:205-7. doi: 10.1192/bja.2020.29

121. Moriates C, Valencia V. Emerging principles for health system value improvement programmes. BMJ Qual Saf. (2019) 28:434. doi: 10.1136/bmjqs-2019-009427

122. Marzorati C, Pravettoni G. Value as the key concept in the health care system: how it has influenced medical practice and clinical decision-making processes. J Multidiscip Healthc. (2017) 10:101-6. doi: 10.2147/JMDH.S122383

123. World Health Organization. Gender and COVID- 19: Advocacy Brief, 14 May 2020. Genèva: World Health Organization (2020). Available online at: https://apps.who.int/iris/handle/10665/332080. License: CC BY-NC-SA 3.0 IGO

124. Rahman MA, Islam MR. COVID-19 Pandemic: Community Engagement Could be the Best Approach for Mitigation. Technical Report. Research Gate GmbH (2020). doi: 10.13140/RG.2.2.11147.31521. Available online at: https://www.researchgate.net/publication/342961776

125. Fuhrman S, Kalyanpur A, Friedman S, Tran NT. Gendered implications of the COVID-19 pandemic for policies and programmes in humanitarian settings. BMJ Global Health. (2020) 5:e002624. doi: 10.1136/bmjgh-2020-002624

126. Chootipongchaivat S, Chantarastapornchit V, Kulpeng W, Ceria JA, Tolentino NI, Teerawattananon Y. Vaccination program in a resourcelimited setting: a case study in the Philippines. Vaccine. (2016) 34:48149. doi: 10.1016/j.vaccine.2016.08.014

127. So AD, Woo J. Reserving coronavirus disease 2019 vaccines for global access: cross sectional analysis. BMJ. (2020) 371:m4750. doi: 10.1136/bmj.m4750

128. Meyer H. After a COVID-19 vaccine: collaboration or competition? Health Aff (Millwood). (2020) 39:1856-60. doi: 10.1377/hlthaff.2020. 01732

129. Persad G, Peek ME, Emanuel EJ. Fairly prioritizing groups for access to COVID-19 vaccines. JAMA. (2020). doi: 10.1001/jama.2020. 18513

130. Moodley K, Rennie S, Behets F, Obasa AE, Yemesi R, Ravez L, et al. Allocation of scarce resources in Africa during COVID-19: Utility and justice for the bottom of the pyramid? Dev World Bioeth. (2020) 1:3643. doi: 10.1111/dewb.12280

131. Omer S, Faden R, Kochhar S, Kaslow D, Pallas S, Olayinka F, et al. WHO SAGE Roadmap for Prioritizing Uses of COVID-19 Vaccines in the Context of Limited Supply. Geneva: World Health Organization (2020).

132. Organization WH. WHO SAGE Values Framework for the Allocation and Prioritization of COVID-19 Vaccination, 14 September 2020. Geneva: World Health Organization (2020).

133. Faden R, Saad O, Kochhar S, Kaslow D, Pallas S, Olayinka F, et al. WHO SAGE Values Framework for the Allocation and Prioritization of COVID-19 Vaccination. Genève: WHO (2020).

134. Organization WH. Evidence to Recommendations for COVID-19 Vaccines: Evidence Framework: A Framework to Inform the Assessment of Evidence and Formulation of Subsequent COVID-19 Vaccine Recommendations, 10 December 2020. Geneva: World Health Organization (2020).

135. Vora KS, Sundararajan A, Saiyed S, Dhama K, Natesan S. Impact of COVID-19 on women and children and the need for a gendered approach in vaccine development. Hum Vaccines Immunother. (2020) 16:29327. doi: 10.1080/21645515.2020.1826249

136. Dhama K, Patel SK, Natesan S, Vora KS, Iqbal Yatoo M, Tiwari R, et al. COVID-19 in the elderly people and advances in vaccination approaches. Hum Vaccines Immunother. (2020) 16:2938-43. doi: 10.1080/21645515.2020.18 42683

137. Organization WH. Guidance on Developing a National Deployment and Vaccination Plan for COVID-19 Vaccines: Interim Guidance, 16 November 2020. Geneva: World Health Organization (2020).

138. World Health O. Interim Recommendations for Use of the AZD1222 (ChAdOx1-S [recombinant]) Vaccine Against COVID19 Developed by Oxford University and AstraZeneca: Interim Guidance, 10 February 2021. Geneva: World Health Organization (2021).

139. World Health O. Interim Recommendations for Use of the Moderna mRNA1273 Vaccine Against COVID-19: Interim Guidance, 25 January 2021. Geneva: World Health Organization (2021).

140. World Health O. Background Document on the mRNA-1273 Vaccine (Moderna) against COVID-19: background document to the WHO Interim recommendations for use of the mRNA-1273 vaccine (Moderna), 3 February 2021. Geneva: World Health Organization (2021).

141. World Health O. Interim Recommendations for Use of the Pfizer-BioNTech COVID-19 Vaccine, BNT162b2, Under Emergency Use Listing: Interim Guidance, 8 January 2021. Geneva: World Health Organization (2021).

142. World Health O. Background Document on the mRNA Vaccine BNT162b2 (Pfizer-BioNTech) Against COVID-19: Background Document to the WHO Interim Recommendations for Use of the Pfizer-BioNTech COVID-19 Vaccine, BNT162b2, Under Emergency Use Listing, 14 January 2021. Geneva: World Health Organization (2021).

143. OECD. Beyond Containment: Health Systems Responses to Covid-19 in the OECD. Paris: Organization for Economic Co-operation and Development (2020). Available online at: https://read.oecd-ilibrary.org/view

144. Ahmad T, Haroon H, Dhama K, Sharun K, Khan FM, Ahmed I, et al. Biosafety and biosecurity approaches to restrain/contain and counter SARSCoV-2/COVID-19 pandemic: a rapid-review. Turk J Biol. (2020) 44:13245. doi: 10.3906/biy-2005-63

145. Aziz AB, Raqib R, Khan WA, Rahman M, Haque R, Alam M, et al. Integrated Control of COVID-19 in Resource Poor Countries. Dhaka: Elsevier (2020). p. 98-101. doi: 10.1016/j.ijid.2020.09.009

146. Emilio Granados F, Richard L, Marie Sophie M, et al. COVID-19 Risks Outlook: A Preliminary Mapping and Its Implications. Geneva: World Economic Forum (2020). Available online at: www.weforum.org

147. Koçak Tufan Z, Kayaaslan B. Crushing the curve, the role of national and international institutions and policy makers in COVID-19 pandemic. Turk J Med Sci. (2020) 50:495-508. doi: 10.3906/sag-20 04-167

148. Yaya S, Otu A, Labonté R. Globalisation in the time of COVID19: repositioning Africa to meet the immediate and remote challenges. Global Health. (2020) 16:51. doi: 10.1186/s12992-020-0 0581-4

149. Agarwal V, Sharma S, Gupta L, Misra DP, Davalbhakta S, Agarwal $\mathrm{V}$, et al. COVID-19 and psychological disaster preparedness - an unmet need. Disaster Med Public Health Prep. (2020) 14:387-90. doi: 10.1017/dmp.2020.219

150. Aktar MA, Alam MM, Al-Amin AQ. Global economic crisis, energy use, CO2 emissions, and policy roadmap amid COVID-19. Sustain Prod Consum. (2021) 26:770-81. doi: 10.1016/j.spc.2020.12.029

151. Vidya CT, Prabheesh KP. Implications of COVID-19 pandemic on the global trade networks. Emerg Mark Finan Trade. (2020) 56:240821. doi: 10.1080/1540496X.2020.1785426

152. Bank W. The Global Economic Outlook During the COVID-19 Pandemic: A Changed World. Washington, DC: World Bank Feature Story (2020).

153. Abdalla SM, Maani N, Ettman CK, Galea S. Claiming health as a public good in the post-COVID-19 era. Development. (2020) 1-5. doi: 10.1057/s41301-020-00255-z. [Epub ahead of print].

154. Dhama K, Khan S, Tiwari R, Sircar S, Bhat S, Malik YS, et al. Coronavirus Disease 2019-COVID-19. Clin 
Microbiol Rev. (2020) 33:e00028-20. doi: 10.1128/CMR.00 028-20

155. Rabaan AA, Al-Ahmed SH, Sah R, Tiwari R, Yatoo MI, Patel SK, et al. SARSCoV-2/COVID-19 and advances in developing potential therapeutics and vaccines to counter this emerging pandemic. Ann Clin Microbiol Antimicrob. (2020) 19:40. doi: 10.1186/s12941-020-00384-w

156. Iqbal Yatoo M, Hamid Z, Parray OR, Wani AH, Ul Haq A, Saxena A, et al. COVID-19 - Recent advancements in identifying novel vaccine candidates and current status of upcoming SARS-CoV-2 vaccines. Hum Vaccines Immunother. (2020) 16:2891-904. doi: 10.1080/21645515.2020.1788310
Conflict of Interest: The authors declare that the perspective document was conducted in the absence of any commercial or financial relationships that could be construed as a potential conflict of interest.

Copyright $\odot 2021$ Gashaw, Hagos and Sisay. This is an open-access article distributed under the terms of the Creative Commons Attribution License (CC BY). The use, distribution or reproduction in other forums is permitted, provided the original author(s) and the copyright owner(s) are credited and that the original publication in this journal is cited, in accordance with accepted academic practice. No use, distribution or reproduction is permitted which does not comply with these terms. 